\title{
Electronic structure and bonding in unligated and ligated Fe" porphyrins
}

\author{
Meng-Sheng Liao and Steve Scheiner ${ }^{\text {a) }}$ \\ Department of Chemistry and Biochemistry, Utah State University, Logan, Utah 84322-0300
}

(Received 22 October 2001; accepted 11 December 2001)

\begin{abstract}
The electronic structure and bonding in a series of unligated and ligated $\mathrm{Fe}^{\mathrm{II}}$ porphyrins $(\mathrm{FeP})$ are investigated by density functional theory (DFT). All the unligated four-coordinate iron porphyrins have a ${ }^{3} A_{2 g}$ ground state that arises from the $\left(d_{x y}\right)^{2}\left(d_{z^{2}}\right)^{2}\left(d_{\pi}\right)^{2}$ configuration. The calculations confirm experimental results on Fe tetraphenylporphine but do not support the resonance Raman assignment of $\mathrm{Fe}$ octaethylporphine as ${ }^{3} E_{g}$, nor the early assignment of $\mathrm{Fe}$ octamethyltetrabenzporphine as ${ }^{5} B_{2 g}$. For the six-coordinate $\mathrm{Fe}-\mathrm{P}(L)_{2}(L=\mathrm{HCN}$, pyridine, $\mathrm{CO})$, the strong-field axial ligands raise the energy of the $\mathrm{Fe} d_{z^{2}}$ orbital, thereby making the iron porphyrin diamagnetic. The calculated redox properties of $\mathrm{Fe}-\mathrm{P}(L)_{2}$ are in agreement with experiment. As models for deoxyheme, the energetics of all possible low-lying states of $\mathrm{FeP}$ (pyridine) and $\mathrm{FeP}(2$-methylimidazole) have been studied in detail. The groundstate configuration of $\mathrm{FeP}(2$-methylimidazole) was confirmed to be high-spin $\left(d_{x y}\right)^{2}\left(d_{z^{2}}\right)^{1}\left(d_{\pi}\right)^{2}\left(d_{x^{2}-y^{2}}\right)^{1}$; FeP (pyridine) is shown to be a poor model for high-spin deoxyheme. (c) 2002 American Institute of Physics. [DOI: 10.1063/1.1447902]
\end{abstract}

\section{INTRODUCTION}

Iron porphyrins play a central role in biology as the active centers or prosthetic groups of hemoproteins. ${ }^{1}$ Consequently, there has been much interest in understanding the electronic structure of these molecules. $\mathrm{Fe}^{\mathrm{II}}$ porphyrins, with six $d$-electrons, can exist as intermediate- $(S=1)$, low- $(S$ $=0)$, and high-spin $(S=2)$ states, depending on the coordination and the environment of the iron ion. ${ }^{2}$ The ground state of unligated, four-coordinate $\mathrm{Fe}^{\mathrm{II}}$ porphyrins, remains controversial. Experimental studies of iron tetraphenylporphine (FeTPP) and iron octaethylporphine (FeOEP) agree that the ground state is of intermediate spin, but differ in the details of the electronic configuration. An ${ }^{3} A_{2 g}$ ground state configuration $\left(d_{x y}\right)^{2}\left(d_{\pi} / d_{x z}=d_{y z}\right)^{2}\left(d_{z^{2}}\right)^{2}$ was indicated by Mössbauer, ${ }^{3,4}$ magnetic ${ }^{5}$ and proton nuclear magnetic resonance (NMR) (Refs. 6 and 7) measurements of FeTPP. On the other hand, Raman spectra of FeOEP were interpreted in terms of an ${ }^{3} E_{g}$ state arising from the $\left(d_{x y}\right)^{2}\left(d_{\pi}\right)^{3}\left(d_{z^{2}}\right)^{1}$ configuration. ${ }^{8}$

From the theoretical perspective, Hartree-Fock (HF) calculations on the unsubstituted iron porphine $(\mathrm{FeP})$ agree with experiment that ${ }^{3} A_{2 g}$ is indeed the most stable of various triplet states, ${ }^{9-12}$ but find a high-spin ${ }^{5} A_{1 g}$ state to be even lower in energy by more than $1 \mathrm{eV} .^{9,10,12}$ The inclusion of correlation helps to repair this artificial advantage of the quintet, ${ }^{12}$ but does not fully reverse the incorrect order of spin multiplicities. In the same vein, recent CASPT2 and MRMP studies ${ }^{13}$ of $\mathrm{FeP}$ remain in disagreement with experiment ${ }^{3-8}$ in predicting the lowest state to be ${ }^{5} A_{1 g}$. The large magnetic moment observed for FeTPP (Ref. 3) was thought by these authors to support their high-spin ground

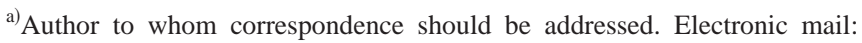
scheiner@cc.usu.edu
}

state. However, a detailed ligand-field calculation ${ }^{5}$ concluded that this large moment is based on a coupling between the ${ }^{3} A_{2 g}$ and ${ }^{3} E_{g}$ states. Moreover, the core size of the porphyrin ring of the ${ }^{5} A_{1 g}$ state is considerably larger than the experimental finding. When coupled with the correlation between $R(\mathrm{Fe}-\mathrm{N})$ and spin state, ${ }^{2}$ this size of FeTPP is incompatible with a high-spin ground state, but rather argues for an intermediate spin.

There have also been multiple scattering $X_{\alpha}\left(\mathrm{MS}-X_{\alpha}\right)$ [Ref. 14(a)] and semiempirical INDO-CI [Ref. 14(b)] calculations on the same four-coordinate system, but the calculated relative energies for the various configurations are questionable since these methods are quite approximate. More recently, Delley ${ }^{15}$ and Matsuzawa et al. ${ }^{16}$ performed local DFT calculations on FeP, whereby they predict an ${ }^{3} E_{g}$ ground state, consistent with the earlier Raman study. ${ }^{8}$ Probably, the best and most accurate calculations on the electronic structure of FeP to date are the very recent nonlocal DFT calculations by Kozlowski et al. ${ }^{17}$ who found the ground state to be ${ }^{3} A_{2 g}$ in agreement with most of the experiments.

There is a novel four-coordinate $\mathrm{Fe}^{\mathrm{II}}$ porphyrin complex, iron octamethyltetrabenzporphine (FeOTBP), which is surprisingly different than FeTPP or FeOEP. Its magnetic moment was reported to be $5.9 \mu_{B},{ }^{18}$ suggesting a high-spin ground state. Furthermore, a ${ }^{5} B_{2 g}$ ground state was based first on the assumption of a similar state for FeTPP, which was later shown to be erroneous. ${ }^{3-8}$ The other factor was the positive electric field gradient $V_{z z}$ in the Mössbauer spectra, but this provides only an indirect suggestion of ground state at best. Recent data have supported the fact that the lowest energy quintet is not ${ }^{5} B_{2 g}$ at all but rather ${ }^{5} A_{1 g} .{ }^{9-17}$ Hence, there are is no conclusive evidence to date of the true ground state. The specific reasons underlying the electronic ground state of $\mathrm{Fe}^{\mathrm{II}}$ in FeOTBP would be of particular interest, since 
the ground state is ${ }^{3} A_{2 g}$ in FeTPP and a structurally similar iron phthalocyanine $(\mathrm{FePc}){ }^{19}$ Yet there have to this point been no theoretical studies of this complex.

Iron porphyrins have a strong attraction for additional axial ligands, to which their electronic structures are sensitive. Ligated $\mathrm{Fe}^{\mathrm{II}}$ porphyrins typically exhibit two spin states, $S=0$ and 2, depending upon the coordination number and the axial ligand-field strength. Six-coordinate $\mathrm{Fe}^{\mathrm{II}}$ porphyrins are usually found in a low-spin $(S=0)$ state [e.g., FeTPP(pyridine) ${ }_{2},{ }^{20}$ FeTPP(piperidine) ${ }_{2},{ }^{21}$ FeTPP(pyridine) (CO) (Ref. 22)]. A complex with tetrahydrofuran $\left(\mathrm{C}_{5} \mathrm{H}_{8} \mathrm{O}\right)$ ligands, FeTPP $(\mathrm{THF})_{2}$, seems to be an exception, wherein the $\mathrm{Fe}^{\mathrm{II}}$ ion was reported to be in a high spin state. ${ }^{23}$ The reason for this deviation, and the electronic structure of FeTPP $(\mathrm{THF})_{2}$ remains poorly understood. ${ }^{24}$

High-spin $(S=2)$ states are generally encountered in five-coordinate $\mathrm{Fe}^{\mathrm{II}}$ porphyrin complexes, wherein the $\mathrm{Fe}$ atom lies significantly out of the porphyrin plane, towards the axial ligand. The deoxy form of both myoglobin $(\mathrm{Mb})$ and hemoglobin $(\mathrm{Hb})$ has been well characterized in highspin states; ${ }^{25(a)}$ they include a single axial imidazole ligand (from the proximal histidine) wherein the Fe lies 0.42-0.63 $\AA$ above the porphyrin plane. ${ }^{25(\mathrm{~b})}$ Among the synthetic fivecoordinate $\mathrm{Fe}^{\mathrm{II}}$ porphyrins, a well known high-spin complex is $\operatorname{FeTPP}(2-\mathrm{MeIm})$ with 2-methylimidazole as its axial ligand $;{ }^{26} \mathrm{Fe}$ lies $0.42 \AA$ above the porphyrin plane. This system represents a good model for deoxy-Mb and $-\mathrm{Hb}$.

To help elucidate the electronic properties of the $\mathrm{Fe}^{\mathrm{II}}$ deoxyheme complexes in hemoprotein, and the origin of the Fe out-of-plane displacements, theoretical studies have been carried out for model systems that consist of iron porphine (FeP) with an axial nitrogenous ligand. In early ab initio HF calculations, ${ }^{10,27} \mathrm{NH}_{3}$ and pyridine (py) were used to mimic the imidazole of the heme. The HF results on the transition metal systems are dubious due to lack of electron correlation. Also, $\mathrm{NH}_{3}$ and py are questionable models of the imidazole ligand. An iron porphine complex with unsubstituted imidazole, FeP(Im), was studied, but again by means of semiempirical methods. ${ }^{28}$

Recently, two different groups have applied DFT methods to $\mathrm{FeP}(\mathrm{Im})$. One study ${ }^{29}$ considered one intermediatespin state ${ }^{3} A\left[\left(d_{x y}\right)^{2}\left(d_{z^{2}}\right)^{2}\left(d_{\pi}\right)^{2}\right]$ and one high-spin state ${ }^{5} A\left[\left(d_{x y}\right)^{1}\left(d_{z^{2}}\right)^{2}\left(d_{\pi}\right)^{2}\left(d_{x^{2}-y^{2}}\right)^{1}\right]$. The ${ }^{3} A$ state was found to be lower in energy than the ${ }^{5} A$ state by $\sim 0.28 \mathrm{eV}$, but when the Fe was displaced $0.40 \AA$ from the porphyrin plane, the relative energies of ${ }^{3} A$ and ${ }^{5} A$ were reversed. In the other DFT study ${ }^{30}$ four states were considered: two intermediate-spin states ${ }^{3} A^{\prime \prime}\left[\left(d_{x y}\right)^{2}\left(d_{z^{2}}\right)^{1}\left(d_{\pi}\right)^{3}\right]$ and $\quad{ }^{3} A^{\prime}\left[\left(d_{x y}\right)^{1}\left(d_{z^{2}}\right)^{1}\left(d_{\pi}\right)^{4}\right]$, one high-spin ${ }^{5} A^{\prime \prime}\left[\left(d_{x y}\right)^{1}\left(d_{z^{2}}\right)^{1}\left(d_{\pi}\right)^{3}\left(d_{x^{2}-y^{2}}\right)^{1}\right], \quad$ and one low-spin ${ }^{1} A^{\prime}\left[\left(d_{x y}\right)^{2}\left(d_{\pi}\right)^{4}\right]$. The intermediate-spin state $\left({ }^{3} A^{\prime \prime}\right)$ was predicted to be slightly lower in energy than the high-spin state, by $0.04 \mathrm{eV}$. However, the calculations using the B3LYP functional may underestimate the separation between the $S$ $=1$ and $S=2$ states (e.g., their B3LYP calculated energy separation between ${ }^{3} A_{2 g}$ and ${ }^{5} A_{1 g}$ states for $\mathrm{FeP}$ is $0.30 \mathrm{eV},{ }^{17}$ in contrast to the experimental value of $0.62 \mathrm{eV}$ ).

Because only a few states were considered out of many possibilities, some questions remain. Various occupations of six electrons in the $d$-orbitals of the iron porphyrins can yield eight possible low-lying states: one low-spin, four intermediate-spin, and three high-spin states. The states considered in the previous DFT studies may not be the lowest, even of their respective spins, for FeP(Im). For example, a $\left(d_{x y}\right)^{2}\left(d_{z^{2}}\right)^{1}\left(d_{\pi}\right)^{2}\left(d_{x^{2}-y^{2}}\right)^{1}$ ground state has been suggested from a proton NMR study of five-coordinate high-spin $\mathrm{Fe}^{\mathrm{II}}$ porphyrin complexes. ${ }^{31}$ This state was ignored by both DFT studies. It is therefore desirable to have more detailed theoretical studies of $\mathrm{FeP}(\mathrm{Im})$, including all plausible electronic states.

In this report, we present a theoretical study of a series of unligated and ligated $\mathrm{Fe}^{\mathrm{II}}$ porphyrins using an $\mathrm{ADF}$ method (see Sec. II) which has proved to be both efficient and reliable for both metal phthalocyanines ${ }^{32}$ and porphyrins. ${ }^{33}$ While the DFT method, based on the KohnSham one-electron equation, is not generally applicable to excited states, it can be used to good effect to calculate the lowest energy state of each symmetry for a particular system. ${ }^{34}$ The good level of agreement between our calculated excitation energies and experiment verifies that the ADF method is useful for studying the relevant excited states in the iron porphyrin complexes. The main aims are as follows:

A comparison of FeP, FeTPP, FeOEP, and FeOTBP so as to determine the sensitivity of the electronic structure of the $\mathrm{Fe}^{\mathrm{II}}$ ion in an iron porphyrin to the precise nature of the tetradentate system.

(ii) It is known that axial ligation has a substantial influence on the redox properties of metal porphyrins, ${ }^{35(a)}$ and many electrochemical studies have been performed with the aim of elucidating the relationship between the electronic structure and these redox properties. The effects of different axial ligands (HCN, pyridine, $\mathrm{CO}$ ) on the electronic structure and redox properties of the $\mathrm{Fe}^{\mathrm{II}}$ porphyrin are hence examined here in some detail.

(iii) A deeper insight into the electronic structure and bonding in the deoxyheme model complex. We have chosen to use 2-MeIm as the axial ligand. $\mathrm{FeP}(2-$ MeIm) should be more closely related to biological systems than is $\mathrm{FeP}(\mathrm{Im})$ since the deoxy-Mb and $-\mathrm{Hb}$ models all have a 2-MeIm ligand. ${ }^{36(a)}$ The methyl group probably experiences a repulsive interaction with the porphyrin ring which is suggested to be a prerequisite for hemochrome formation. ${ }^{36(\mathrm{~b})}$ Moreover, the crystal structure of an analogous system FeTPP(2-MeIm) EtOH is available, making possible a straightforward comparison with experiment. We consider all possible low-lying states with different configurations of $d$-electrons. To further probe the bonding interaction between the nitrogenous ligand and the iron porphyrin, calculations have also been made for $\mathrm{FeP}(\mathrm{py})$ which will also cast light on the validity of the $\mathrm{FeP}($ py) model.

\section{COMPUTATIONAL METHOD}

Calculations were carried out with the Amsterdam Density Functional (ADF) program package developed by 


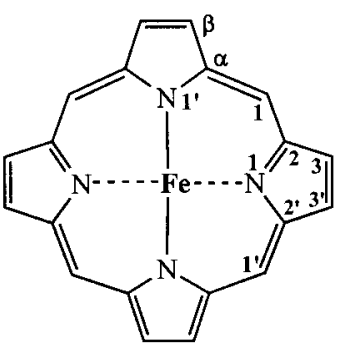

(a) Iron Porphine (model system) (FeP)

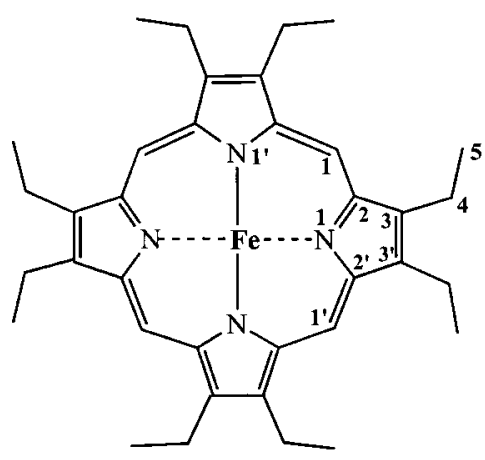

(c) Iron Octaethylporphine (FeOEP)

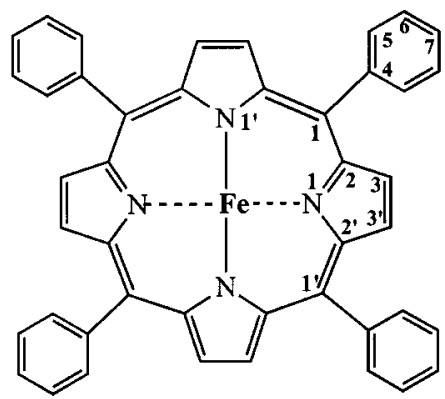

(b) Iron meso-Tetraphenylporphine (FeTPP)

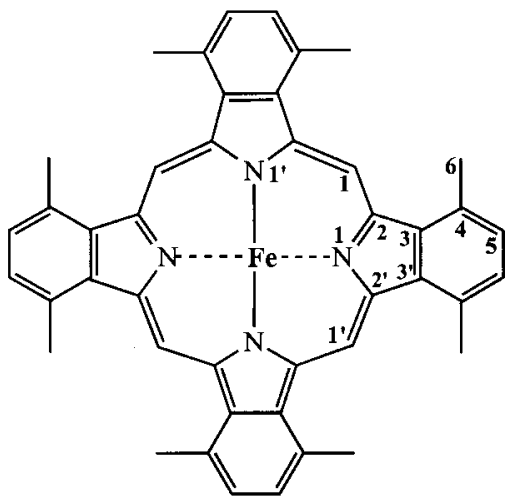

(d) Iron Octamethyltetrabenzporphine (FeOTBP)
FIG. 1. Molecular structures and atomic numbering schemes of (a) FeP, (b) FeTPP, (c) FeOEP, and (d) $\mathrm{FeOTBP}$ ( $\mathrm{H}$ atoms are omitted).
Baerends et $a .^{37}$ The inner core orbitals, i.e., $1 s$ for $\mathrm{C} / \mathrm{N} / \mathrm{O}$ and $1 s-2 p$ for $\mathrm{Fe}$, are kept frozen. The valence shells $(1 s$ for $\mathrm{H}, 2 s-2 p$ for $\mathrm{C} / \mathrm{N} / \mathrm{O}$, and $3 s-4 s$ for $\mathrm{Fe}$ ) are expanded in triple- $\zeta$ STO basis sets, augmented by one polarization function. Single- $\zeta$ STOs are used for core orthogonalization. The exchange-correlation potential is based on the densityparametrized form of Vosko, Wilk, and Nusair. ${ }^{38}$ The nonlocal corrections are based on Becke's gradient functional for exchange $^{39}$ and Perdew's gradient functional for correlation, ${ }^{40}$ and are treated by a fully self-consistent method. Relativistic corrections of the valence electrons are calculated using the quasirelativistic method due to Ziegler et $a l^{41}$

\section{RESULTS AND DISCUSSION}

\section{A. FeP, FeTPP, FeOEP, and FeOTBP}

The molecular structures and atomic numbering schemes of the four-coordinate iron porphyrins are illustrated in Fig. 1. Consistent with previous calculations, ${ }^{33}$ all systems were assumed to belong to the $D_{4 h}$ point group. The four phenyl groups of TPP were assumed to be perpendicular to the porphine plane, based upon the steric interaction between the phenyl and porphinato hydrogen atoms.

Taking the $z$-axis as perpendicular to the porphyrin plane, the five $\mathrm{Fe} 3 d$-orbitals transform as $a_{1 g}\left(d_{z^{2}}\right)$, $b_{1 g}\left(d_{x^{2}-y^{2}}\right), e_{g}\left(d_{\pi}\right.$, i.e., $d_{x z}$ and $\left.d_{y z}\right)$, and $b_{2 g}\left(d_{x y}\right)$. Different occupations of six electrons in these $d$-orbitals yield eight possible low-lying electronic states. Geometry optimization was performed for all states of each molecule. The optimized bond lengths for the molecules in the ${ }^{3} A_{2 g}$ ground state are collected in Table I, together with available experimental data of FeTPP in the crystal. ${ }^{3}$ The $\mathrm{Fe}-\mathrm{N}$ bond lengths $\left(R_{\mathrm{Fe}-\mathrm{N}}\right)$ in FeP and FeTPP are similar $(\sim 1.97 \AA)$, shorter than in FeOEP $(2.00 \AA)$, which is in turn shorter than the $2.03 \AA$ of FeOTBP. This pattern is repeated for the $\mathrm{C}_{2}-\mathrm{C}_{3}$ and $\mathrm{C}_{3}-\mathrm{C}_{3}^{\prime}$ bonds. The bond between $\mathrm{N}$ and $\mathrm{C}_{2}$ is shorter for FeOTBP than for the other three systems, and FeTPP has the longest $\mathrm{C}_{1}-\mathrm{C}_{2}$ bond. The agreement between the calculated and the experimental data is excellent; the largest deviation for bond length is $0.03 \AA$, and $1.5^{\circ}$ for bond angle (not shown in the table).

The energetic orderings of the various states are displayed in Table II, along with the $\mathrm{Fe}-\mathrm{N}$ bond length of each. The lowest energy electronic configuration of all four systems corresponds to $[\cdots]\left(b_{2 g}\right)^{2}\left(a_{1 g}\right)^{2}\left(1 e_{g}\right)^{2}$, a ${ }^{3} A_{2 g}$ state,

TABLE I. Calculated bond lengths $(\AA)$ in various iron porphyrin systems in the ${ }^{3} A_{2 g}$ ground state. Atomic labels from Fig. 1 .

\begin{tabular}{lcccc}
\hline \hline & FeP & FeTPP & FeOEP & FeOTBP \\
\hline$R_{\mathrm{Fe}-\mathrm{N}}$ & 1.975 & $1.970(1.972)^{\mathrm{a}}$ & 1.998 & 2.031 \\
$R_{\mathrm{N}-\mathrm{C} 2}$ & 1.390 & $1.396(1.382)$ & 1.391 & 1.381 \\
$R_{\mathrm{C} 1-\mathrm{C} 2}$ & 1.384 & $1.393(1.392)$ & 1.385 & 1.385 \\
$R_{\mathrm{C} 2-\mathrm{C} 3}$ & 1.436 & $1.435(1.436)$ & 1.446 & 1.457 \\
$R_{\mathrm{C} 3-\mathrm{C} 3^{\prime}}$ & 1.366 & $1.364(1.353)$ & 1.381 & 1.416 \\
\hline \hline
\end{tabular}

${ }^{a}$ Values in parentheses represent $\mathrm{x}$-ray diffraction data for crystalline FeTPP, Ref. 3. 
TABLE II. Calculated relative energies $(E, \mathrm{eV})$ and Fe-N bond lengths $(R, \AA)$ for different configurations in FeP, FeTPP, FeOEP, and FeOTBP.

\begin{tabular}{|c|c|c|c|c|c|c|c|c|c|c|}
\hline \multicolumn{4}{|c|}{ Configuration } & \multirow[b]{2}{*}{ State } & \multicolumn{4}{|c|}{$E^{\text {relative }}$} & \multicolumn{2}{|c|}{$R_{\mathrm{Fe}-\mathrm{N}}{ }^{\mathrm{a}}$} \\
\hline$b_{2 g} / d_{x y}$ & $a_{1 g} / d_{z^{2}}$ & $1 e_{g} / d_{\pi}$ & $b_{1 g} / d_{x^{2}-y^{2}}$ & & $\mathrm{FeP}$ & FeTPP & $\mathrm{FeOEP}$ & FeOTBP & $\mathrm{FeP}$ & FeOTBP \\
\hline 2 & 2 & 2 & 0 & ${ }^{3} A_{2 g}$ & 0 & 0 & 0 & 0 & 1.98 & 2.03 \\
\hline 2 & 1 & 3 & 0 & ${ }^{3} E_{g}(A)$ & 0.12 & $0.12(0.07)^{\mathrm{b}}$ & 0.18 & $0.13(0.11)^{\mathrm{c}}$ & 1.98 & 2.02 \\
\hline 1 & 1 & 4 & 0 & ${ }^{3} B_{2 g}$ & 0.26 & 0.28 & 0.36 & $0.23(0.20)$ & 1.98 & 2.03 \\
\hline 1 & 2 & 3 & 0 & ${ }^{3} E_{g}(B)$ & 0.74 & 0.72 & 0.80 & $0.78(0.76)$ & 1.98 & 2.02 \\
\hline 1 & 2 & 2 & 1 & ${ }^{5} A_{1 g}$ & 0.71 & $0.75(0.62)^{d}$ & 0.52 & $0.49(0.57)$ & 2.06 & 2.10 \\
\hline 1 & 1 & 3 & 1 & ${ }^{5} E_{g}$ & 0.85 & 0.89 & 0.71 & $0.63(0.70)$ & 2.06 & 2.09 \\
\hline 2 & 1 & 2 & 1 & ${ }^{5} B_{2 g}^{g}$ & 1.05 & 1.09 & 0.87 & $0.83(0.91)$ & 2.06 & 2.10 \\
\hline 2 & 0 & 4 & 0 & ${ }^{1} A_{1 g}$ & 1.49 & 1.51 & 1.58 & & 1.98 & \\
\hline
\end{tabular}

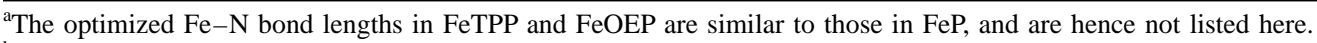

${ }^{b}$ Experimental value from Mössbauer study, Ref. 4.

${ }^{c}$ Values in parentheses refer to iron tetrabenzoporphine (FeTBP).

${ }^{\mathrm{d}}$ Experimental value from magnetic susceptibility study, Ref. 5.

in agreement with the experimental assignment of FeTPP. ${ }^{3-7}$ Hence, the calculation does not support the experimental assignment of unligated FeOTBP as a high-spin $(S=2)$ state. $^{18}$ The ${ }^{3} E_{g}$ state is second lowest, between 0.12 and $0.18 \mathrm{eV}$ higher in energy. Mössbauer studies of FeTPP suggest a separation of $1.35 \times 435 \mathrm{~cm}^{-1}(0.07 \mathrm{eV})$ between the ${ }^{3} A_{2 g}$ and ${ }^{3} E_{g}$ states, ${ }^{4}$ agreeing very well with the calculated value. An earlier assignment of FeOEP as ${ }^{3} E_{g}$ based on the resonance Raman spectra ${ }^{8}$ is thus not supported by the calculation. This state is succeeded by two other triplets, ${ }^{3} B_{2 g}$ and another ${ }^{3} E_{g}$, in that order.

The lowest energy quintet is ${ }^{5} A_{1 g}$, rather close in energy to the higher-lying ${ }^{3} E_{g}$, for FeP and FeTPP. This state lies $0.75 \mathrm{eV}$ above ${ }^{3} A_{2 g}$ for the latter system, again in good agreement with a magnetic susceptibility measurement that yielded a value of $5000 \mathrm{~cm}^{-1}(0.62 \mathrm{eV}) .^{5}$ Its energy is reduced somewhat for FeOEP and FeOTBP, placing the ${ }^{5} A_{1 g}$ state clearly below ${ }^{3} E_{g}(B)$.

Finally, in order to examine the effects of the terminal methyl groups of FeOTBP on the electronic structure of the $\mathrm{Fe}^{\mathrm{II}}$, these groups were removed, yielding iron tetrabenzoporphine (FeTBP). The calculated values (presented in parentheses in Table II) show that this methyl effect is small, probably reflecting the remoteness of the methyl groups from the central metal.

Figure 2 illustrates the energies of the upper occupied and lower vacant MOs for the ground states of the four molecules ( $\mathrm{FeP}$ is shown twice in order to best characterize the larger molecules as perturbations from this starting point). The populations of Fe $3 d$-like MOs are reported in parentheses so as to assist in an interpretation. Considering first FeP, all the $\mathrm{Fe} d$-orbitals are higher in energy relative to the ligand $\pi$-orbitals. The antibonding $d_{x^{2}-y^{2}}$ orbital $\left(b_{1 g}\right)$ is particularly destabilized through its interaction with the porphyrin nitrogens. The HOMO and LUMO, respectively, of the porphyrin ring correspond to $a_{2 u}$ and $2 e_{g}\left(\pi^{*}\right)$; the Fe $d_{\pi}$ orbitals make a contribution of $\sim 10 \%$ to the latter within the complex. The occupied $a_{2 u}$ and $a_{1 u}$ of the porphyrin are nearly degenerate and well separated from lower-lying levels, a feature of free-base porphine $\left(\mathrm{H}_{2} \mathrm{P}\right){ }^{42}$

The outer MOs of FeTPP and FeOEP are similar to those of FeP, albeit somewhat destabilized. Phenyl groups attached to the meso-sites of the porphyrin skeleton have little effect upon the calculated orbital energies because the phenyl groups are normal to the plane of the ring and have little or no conjugation with the porphyrin system. In contrast, pyrrolic $\beta$-ethyl groups of FeOEP cause an upshift of $\sim 0.5 \mathrm{eV}$ in all valence MOs.

The electronic structure of FeOTBP differs somewhat from that of $\mathrm{FeP}$ in some intriguing ways. Four benzo groups added to the $\mathrm{P}$ ring remove the near degeneracy of $a_{2 u}$ and $a_{1 u}$, raising the latter to a surprising degree. The perturbation of the benzo rings in OTBP on the electronic structure of $\mathrm{Fe}^{\mathrm{II}}$ is, on the other hand, rather small. Although the $b_{1 g}$ $\left(d_{x^{2}-y^{2}}\right)$ orbital is lowered in FeOTBP, it nonetheless remains unoccupied.

Referring again to Table II, it might be noted that the optimized $\mathrm{Fe}-\mathrm{N}$ bond lengths for the $S=2$ states are $0.08 \AA$ longer than the same bonds for the $S=1$ states. This difference can be attributed to an electron in the antibonding

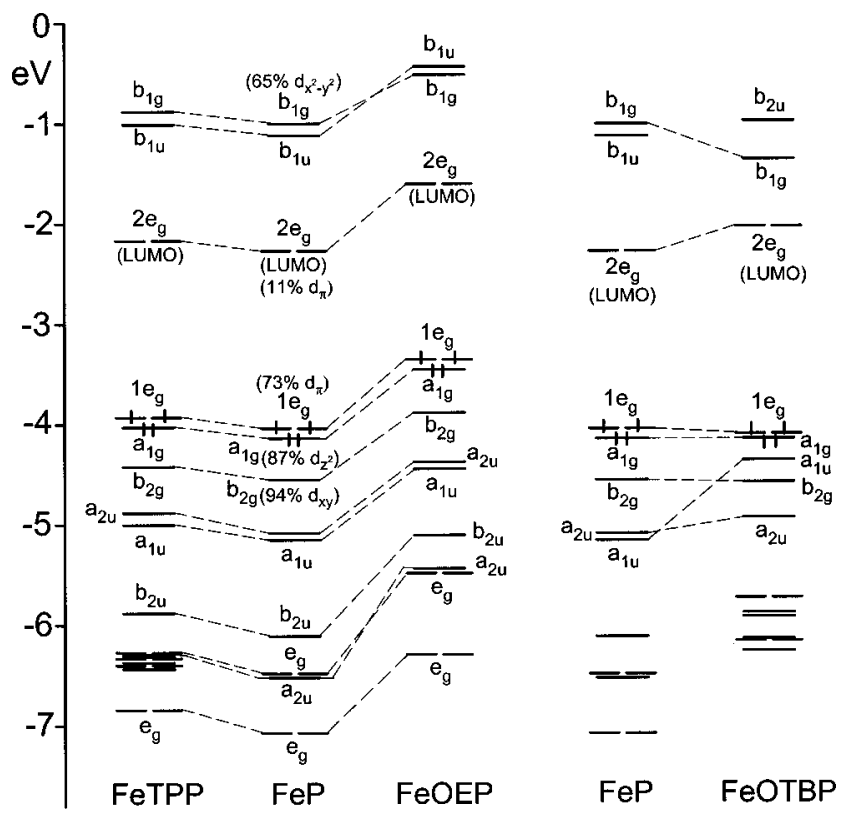

FIG. 2. Orbital energy levels for the outer orbitals of FeP, FeTPP, FeOEP, and $\mathrm{FeOTBP}$. 
TABLE III. Mulliken orbital populations and atomic charges $(Q)$ on Fe.

\begin{tabular}{lcccc}
\hline \hline & FeP & FeTPP & FeOEP & FeOTBP \\
\hline $3 d$ & 6.57 & 6.58 & 6.59 & 6.55 \\
$4 s$ & 0.44 & 0.46 & 0.46 & 0.45 \\
$4 p$ & 0.33 & 0.33 & 0.34 & 0.36 \\
$Q_{\mathrm{Fe}}$ & 0.66 & 0.63 & 0.61 & 0.63 \\
\hline \hline
\end{tabular}

$d_{x^{2}-y^{2}}$ orbital in the $S=2$ state. Permitting this $\mathrm{Fe}-\mathrm{N}$ bond elongation lowers the energy by $\sim 0.4 \mathrm{eV}$ with respect to the $S=1$ state. The calculations reveal that for any given iron porphyrin, the principal factor determining the $\mathrm{Fe}-\mathrm{N}$ bond length is the occupancy of the $d_{x^{2}-y^{2}}$ orbital.

The gross populations of the Fe $3 d, 4 s$, and $4 p$ orbitals are reported in Table III, along with this atom's Mulliken atomic charge. This "effective" charge of Fe, which remains nearly constant from one molecule to another, is around $0.6 e$, quite different than the classic picture of $\mathrm{Fe}^{2+}$ (porphyrin) ${ }^{2-}$, wherein two $4 s$ electrons have been lost by the metal. The Mulliken populations of the orbitals are nonintegral and do not reflect the formal orbital occupations. The Fe $4 s$ and $4 p$ populations are $\sim 0.45$ and $\sim 0.35 e$, respectively, and are insensitive to the nature of the porphyrin. There is about 0.6 additional electron in Fe $3 d$-orbitals, beyond the classical ligand field $d^{n-2}$ configuration. This increase in Fe $3 d$-populations can be ascribed to backdonation from the $\pi$-orbitals of the porphyrin skeleton.

Table IV presents the calculated values for $\mathrm{Fe}$-porphyrin bond energies $\left(E_{\text {bond }}\right)$, ionization potentials (IP) (for several outer MOs), and electron affinities (EA), together with available experimental data. ${ }^{43-45} E_{\text {bond }}$ is defined as the energy required to pull the $\mathrm{Fe}$ apart from the porphyrin,

$$
-E_{\text {bond }}=E(\mathrm{FeP})-\{E(\mathrm{Fe})+E(\mathrm{P})\}
$$

(here $\mathrm{P}=\mathrm{P}$, TPP, OEP, or OTBP).

The IPs and EAs were calculated by the so-called $\Delta \mathrm{SCF}$ method which computes each property as the difference in total energy between the neutral and ionized species.

The calculated bond energy of $10.3 \mathrm{eV}$ for FeP is reduced slightly to $10.1 \mathrm{eV}$ for FeTPP and FeOEP, suggesting that the peripheral substituents weaken the interaction between the porphyrin and the metal by roughly $0.2 \mathrm{eV}$. The larger ring size of OTBP gives rise to a smaller ligand field, and the Fe-OTBP bond energy is $1.0 \mathrm{eV}$ smaller than for FeTPP. Mössbauer data indicate that the strength of the bond to the tetradentate ligands is stronger for TPP than for OTBP, ${ }^{18}$ consistent with the calculation.

Despite the slightly higher energy of the $1 e_{g} \mathrm{MO}$ evident in Fig. 2, the $\mathrm{IP}_{1}$ 's for FeP, FeTPP, and FeOEP all result from Fe $a_{1 g}\left(d_{z^{2}}\right)$ ionization. The first ionization potential $\left(\mathrm{IP}_{1}\right)$ of $\mathrm{FeP}(6.3 \mathrm{eV})$, is reduced by $0.3 \mathrm{eV}$ in FeTPP, and by $0.8 \mathrm{eV}$ in FeOEP, consistent with the orbital energy shifts diagrammed in Fig. 2. The second-lowest IP is associated also with a Fe $d$-orbital, in this case $d_{x y}$. Gas-phase photoelectron spectra have been reported for FeTPP (Ref. 43) and FeOEP, ${ }^{44}$ where the first IP bands are assigned to an electron ejection from the porphyrin $\pi$ systems because the metal $3 d$-electron bands are hard to detect. ${ }^{44}$ The calculated $a_{2 u}$ IPs (the porphyrin ring HOMO) agree very well with the experimental IP values. In the case of FeOTBP, the dramatic energy increase of the porphyrin $a_{1 u}$ (see Fig. 2) makes this orbital the first one from which an electron is extracted. Its IP is $0.2 \mathrm{eV}$ lower than that of the Fe $a_{1 g}$. This result is suggestive that a change from the metal-centered to a $\pi$-ringcentered reaction can be induced by modifying the structure of the macrocycle. Except for $a_{1 u}$, the other calculated IPs of FeOTBP are comparable to those of FeTPP for the selected outer MOs.

The calculated electron affinities (EA) are all negative, which indicates strong attraction of an electron for each iron porphyrin. An experimental gas-phase EA is available for FeTPP, ${ }^{45}$ and is in excellent agreement with the calculation. The EAs of FeP and FeOEP are about 0.2 and $0.6 \mathrm{eV}$ smaller than that of FeTPP, respectively. Again, the EAs of FeOTBP and FeTPP are comparable.

\section{B. HCN, pyridine, and CO ligands}

This section is concerned with an elucidation of the effects of a pair of axial ligands upon the electronic structure of iron porphyrin. The ligands considered here include $\mathrm{CO}$ as a strong $\pi$-acceptor, and HCN and pyridine (py) which have strong $\sigma$-donor capacity but are relatively weak $\pi$-bonders. FeP was taken as the model iron porphyrin; it is worth reiterating its ability to mimic the essential properties of FeTPP. The pyridine ring plane is perpendicular to the porphine and

TABLE IV. Calculated Fe-porphyrin bond energies ( $\left.E_{\text {bond }}\right)$, ionization potentials (IP), and electron affinities (EA), all in units of $\mathrm{eV}$.

\begin{tabular}{lccccc}
\hline \hline & FeP & FeTPP & FeOEP & FeOTBP \\
\hline$E_{\text {bond }}$ & & 10.25 & 10.07 & 10.05 & 9.25 \\
IP & $a_{1 g}$ & $6.29(1 \mathrm{st})$ & $5.97 \quad(1 \mathrm{st})$ & $5.50 \quad(1 \mathrm{st})$ & 6.05 \\
& $b_{2 g}$ & 6.63 & 6.30 & 5.86 & 6.38 \\
& $a_{2 u}$ & 7.00 & $6.55(6.50)^{\mathrm{a}}$ & $6.19(6.06)^{\mathrm{b}}$ & 6.53 \\
& $a_{1 u}$ & 7.01 & 6.65 & 6.21 & $5.81(1 \mathrm{st})$ \\
& $1 e_{g}$ & 7.26 & 6.91 & 6.32 & 6.85 \\
& $b_{2 u}$ & 7.96 & 7.44 & 6.78 & -1.85 \\
\hline \hline
\end{tabular}

${ }^{\mathrm{a}}$ Experimental gas-phase value, Ref. 43.

${ }^{\mathrm{b}}$ Experimental gas-phase value, Ref. 44.

${ }^{\mathrm{c}}$ Experimental gas-phase value, Ref. 45. 
TABLE V. Calculated properties of $\mathrm{FeP}$ with two axial ligands, $\operatorname{FeP}(L)_{2}$ or $\operatorname{FeP}(L)\left(L^{\prime}\right)$.

\begin{tabular}{|c|c|c|c|c|c|}
\hline & $\mathrm{FeP}$ & $\mathrm{FeP}(\mathrm{HCN})_{2}$ & $\mathrm{FeP}(\mathrm{py})_{2}$ & $\mathrm{FeP}(\mathrm{py})(\mathrm{CO})$ & $\mathrm{FeP}(\mathrm{CO})_{2}$ \\
\hline$R_{\mathrm{Fe}-\mathrm{N}(p)}{ }^{\mathrm{a}}(\AA)$ & 1.98 & 2.01 & 2.00 & $2.01(2.02)^{\mathrm{e}}$ & 2.02 \\
\hline$R_{\mathrm{Fe}-L}(\AA)$ & & 1.86 & 2.02 & $2.09(2.10)$ & 1.82 \\
\hline$R_{\mathrm{Fe}-L^{\prime}}(\AA)$ & & & & $1.75(1.77)$ & \\
\hline$R_{\mathrm{Ct}: \mathrm{Fe}} \mathrm{b}(\AA)$ & & & & $0.02(0.02)$ & \\
\hline$Q_{\mathrm{Fe}}$ & 0.66 & 0.54 & 0.73 & 0.51 & 0.34 \\
\hline$Q_{L}$ & & 0.11 & 0.19 & 0.23 & 0.11 \\
\hline$Q_{L^{\prime}}$ & & 0.11 & 0.19 & 0.04 & 0.11 \\
\hline $\begin{array}{l}E_{\text {bond }}\left[\mathrm{FeP}-(L)_{2}\right]^{\mathrm{c}} \\
(\mathrm{eV})\end{array}$ & & 1.04 & 1.45 & 2.00 & 2.06 \\
\hline \multirow[t]{3}{*}{$\mathrm{IP}^{\mathrm{d}}(\mathrm{eV})$} & $6.29\left(a_{1 g} / d_{z^{2}}\right)$ & $6.38\left(P-a_{2 u}\right)$ & $5.66\left(1 b_{2 g} / d_{x z}\right)$ & $6.50\left(a_{1} / d_{x y}\right)$ & $6.81\left(P-a_{2 u}\right)$ \\
\hline & $6.63\left(b_{2 g} / d_{x y}\right)$ & $6.41\left(1 e_{g} / d_{\pi}\right)$ & $5.70\left(1 b_{3 g} / d_{y z}\right)$ & $6.54\left(P-a_{1}\right)$ & $7.27\left(1 e_{g} / d_{\pi}\right)$ \\
\hline & $7.00\left(P-a_{2 u}\right)$ & $6.48\left(b_{2 g} / d_{x y}\right)$ & $\begin{array}{ll}5.91 & \left(a_{1 g} / d_{x y}\right) \\
6.34 & \left(P-b_{1 u}\right)\end{array}$ & $\begin{array}{l}6.69\left(1 b_{1} / d_{x z}\right) \\
6.70\left(1 b_{2} / d_{y z}\right)\end{array}$ & $7.34\left(b_{2 g} / d_{x y}\right)$ \\
\hline $\mathrm{EA}(\mathrm{eV})$ & $-1.66\left(1 e_{g} / d_{\pi}\right)$ & $-0.92\left(P-2 e_{g}\right)$ & $-0.99\left(P-2 b_{2 g}\right)$ & $-1.21\left(P-2 b_{1}\right)$ & $-1.38\left(P-2 e_{g}\right)$ \\
\hline
\end{tabular}

${ }^{\mathrm{a}} \mathrm{N}(p)$ denotes porphinato nitrogen atom.

${ }^{\mathrm{b}} \mathrm{Ct}$ denotes the center of the ring and $R_{\mathrm{Ct}: \mathrm{Fe}}$ denotes displacement of the $\mathrm{Fe}$ atom out of the porphinato plane.

${ }^{c}$ Bond energy between FeP and two $L$ ligands.

${ }^{\mathrm{d}}$ The values in the first row in the IP columns represent the first ionization potentials.

${ }^{\mathrm{e}}$ The values in parentheses are the x-ray diffraction data for crystal FeTPP(py)(CO), Ref. 22.

bisects the $\mathrm{N}-\mathrm{Fe}-\mathrm{N}$ angles of the latter. This orientation minimizes steric interaction between pyridine hydrogens and porphinato nitrogens. $\mathrm{FeP}(\mathrm{HCN})_{2}$ and $\mathrm{FeP}(\mathrm{CO})_{2}$ retain the $D_{4 h}$ symmetry of the unligated FeP, while the symmetries of $\mathrm{FeP}(\mathrm{py})_{2}$ and $\mathrm{FeP}(\mathrm{py})(\mathrm{CO})$ are reduced to $D_{2 h}$ and $C_{2 v}$, respectively. The computed properties are collected in Table $\mathrm{V}$, together with the corresponding data of FeP for comparison.

As illustrated in Fig. 3, the most obvious common effect of all the axial ligands is to dramatically raise the energy of the Fe $a_{1 g}\left(d_{z^{2}}\right)$ orbital. The $\mathrm{Fe}^{\mathrm{II}}$ ion in these six-coordinate complexes hence has an unambiguous $\left(d_{x y}\right)^{2}\left(d_{\pi}\right)^{4}$ closedshell ground state (or its equivalent in the different symmetries). The ligands have only a very slight $(0.02-0.04 \AA)$ stretching effect upon the $\mathrm{Fe}-\mathrm{N}$ distance, as evident by the first row of Table V.

\section{1. $\mathrm{FeP}(\mathrm{HCN})_{2}$}

Compared to $\mathrm{FeP}$, all the orbitals in $\mathrm{FeP}(\mathrm{HCN})_{2}$ are shifted upward, except for $1 e_{g}$ which is stabilized. This stabilization may be attributed to $\mathrm{Fe} \rightarrow L \pi^{*}$ back bonding. The first ionization now arises from the porphyrin $a_{2 u}$ although both occupied Fe $b_{2 g}$ and $1 e_{g}$ lie above this orbital. However, the difference in IP between $a_{2 u}$ and $1 e_{g}$ is quite small, precluding a reliable prediction of this issue. The EA of $\mathrm{FeP}(\mathrm{HCN})_{2}$ is much smaller than that of $\mathrm{FeP}$, as the added electron now goes into a high-lying antibonding porphyrin $2 e_{g}$ of the former instead of a more deeply buried $1 e_{g}$. The $Q_{\mathrm{Fe}}$ values in Table $\mathrm{V}$ indicate that $0.12 e$ flows to $\mathrm{Fe}$, due in part to $\sigma$-donation from the HCN ligands. The energy required to separate $\mathrm{FeP}$ from its two $\mathrm{HCN}$ ligands is computed to be $1.04 \mathrm{eV}$, smallest of those reported in Table V.

\section{2. $\mathrm{FeP}(p y)_{2}$}

The py ligands first reduce the symmetry from $D_{4 h}$ to $D_{2 h}$, splitting the $d_{x z}, d_{y z}$ degeneracy. Perhaps more importantly, these ligands cause upshifts in most of the MOs, simi- lar to $\mathrm{HCN}$, but there are some exceptions. The $1 e_{g}$ orbitals in $\mathrm{FeP}(\mathrm{py})_{2}$ shift up instead of down, and the high-lying $b_{1 u}$ is shifted down. The $b_{2 g}\left(d_{x y}\right)$ orbital of FeP is shifted up enough that it (transformed to $a_{1 g}$ ) becomes the HOMO of the system, as occurred in $\mathrm{FeP}(\mathrm{HCN})_{2}$. This orbital is nearly degenerate with $1 b_{2 g}\left(d_{x z}\right)$, which in fact corresponds to the first IP, the smallest of all IPs reported in Table V. This reduction suggests that $\mathrm{FeTPP}(\mathrm{py})_{2}$ will be easier to oxidize than unligated FeTPP. Electrochemical experiments on electronically similar $\operatorname{RuTPP}(\mathrm{py})_{2}$ showed the one-electron oxidation of this complex is metal-centered, ${ }^{46}$ in agreement with the calculation. The pyridine ligands, like HCN, result in a reduction in the electron affinity, due again to the increase in energy of the $2 e_{g}$ LUMO of FeP.

In contrast to $\mathrm{FeP}(\mathrm{HCN})_{2}$ where the $\mathrm{HCN}$ ligands reduce the positive charge on the metal center, the py ligands enhance this charge, indicating a flow of electrons away from $\mathrm{Fe}$. Pyridine binds more strongly to the FeP than does HCN, as evident by the larger $E_{\text {bond }}$ in Table $\mathrm{V}$. The longer axial $\mathrm{Fe}-\mathrm{N}$ bond length in $\mathrm{FeP}(\mathrm{py})_{2}$ can probably be ascribed to the steric interaction between nitrogen atoms of the porphinato core and hydrogen atoms of the py ligand.

\section{3. $F e P(p y)(c O)$}

Replacement of one of the py ligands by $\mathrm{CO}$ leads to a general lowering of all of the occupied MOs. This point is confirmed by observation of an increase in the oxidation potential for $\operatorname{RuTPP}(\mathrm{py})_{2}$ on going to $\operatorname{RuTPP}(\mathrm{py}) \mathrm{CO} .{ }^{46}$ Indeed, many of the orbital perturbations caused by the two py ligands are reversed when one of these ligands is replaced by CO. As a result, the orbital diagram of $\mathrm{FeP}(\mathrm{py})(\mathrm{CO})$ is not entirely dissimilar from that of unliganded $\mathrm{FeP}$, albeit with a change in the symmetry designation of the MOs.

There are, however, a number of interesting facets of $\mathrm{FeP}(\mathrm{py})(\mathrm{CO})$. The IPs of the two $a_{1}$ orbitals, derived from $\mathrm{Fe}-d_{x y}$ and $\mathrm{P}-a_{2 u}$ are very close, suggesting that the oneelectron oxidation may occur either at the central metal or at 


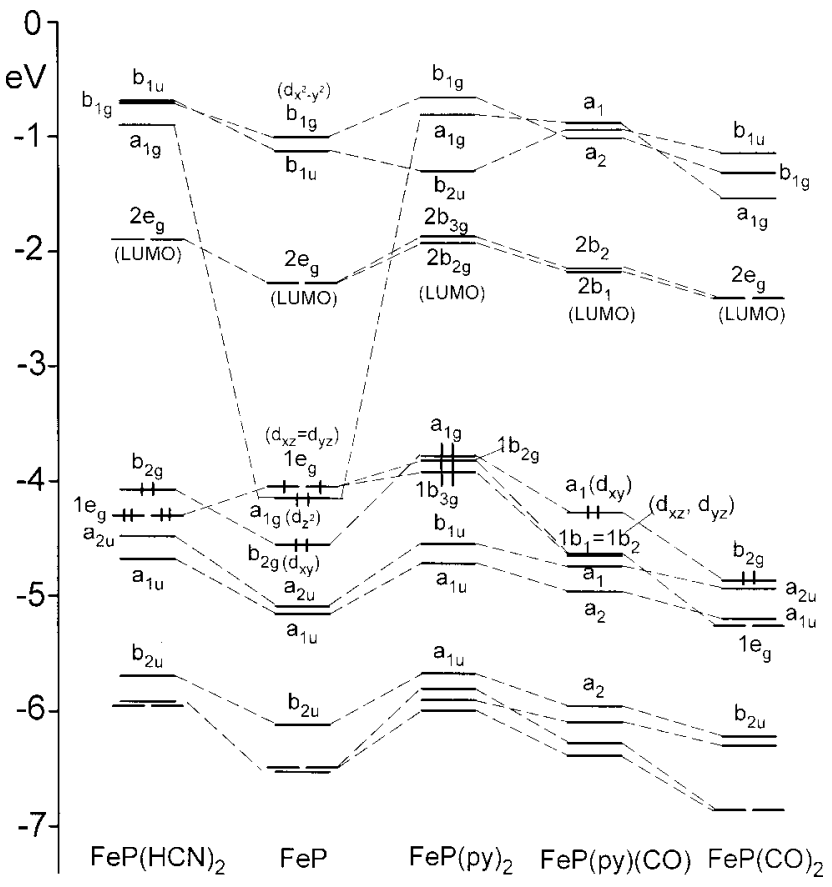

FIG. 3. Orbital energy levels of FeP when complexed with a pair of axial ligands.

the porphyrin ring. Experiments pertaining to the electronically similar RuTPP(py)(CO) show that it undergoes oxidation of the ring to yield $\pi$-cation radicals. ${ }^{46}$ Ionizations from the $1 b_{1}\left(d_{x z}\right)$ and $1 b_{2}\left(d_{y z}\right)$ orbitals, too, require very similar energies, consistent with the near degeneracy in evidence in Fig. 3.

The axial $\mathrm{Fe}-\mathrm{N}(\mathrm{py})$ bond in $\mathrm{FeP}(\mathrm{py})(\mathrm{CO})$ is longer than that in $\mathrm{FeP}(\mathrm{py})_{2}$ or in fact any of the systems in Table $\mathrm{V}$. This stretch may be attributed to the strong trans effect of the $\mathrm{CO}$ ligand. The $\mathrm{Fe}-\mathrm{CO}(\mathrm{ax})$ bond length is short, $1.75 \AA$, indicating strong binding of $\mathrm{CO}$ to $\mathrm{Fe}$. There are $\mathrm{x}$-ray diffraction data available for crystal $\operatorname{FeTPP}(p y)(C O),{ }^{22}$ which are in good agreement with the calculated bond lengths, the error being less than $0.02 \AA$. According to both calculation and experiment, there is a small out-of-plane displacement $(0.02 \AA)$ of the $\mathrm{Fe}$ atom toward the $\mathrm{CO}$ group.

\section{4. $\mathrm{FeP}(\mathrm{CO})_{2}$}

On going from $\mathrm{FeP}(\mathrm{py})(\mathrm{CO})$ to $\mathrm{FeP}(\mathrm{CO})_{2}$, the valence MOs all drop further in energy. Correspondingly, there is an increase of $0.6-0.8 \mathrm{eV}$ in the IPs from Fe $3 d$-like orbitals, while the IPs from the porphyrin orbitals are increased by only about $0.3 \mathrm{eV}$. The first ionization in $\mathrm{FeP}(\mathrm{CO})_{2}$ arises unambiguously from the porphyrin $a_{2 u}$ orbital, the largest $\mathrm{IP}_{1}$ of all the systems under consideration. The charge assigned to the Fe atom is least positive in this complex, suggesting the largest degree of charge donation to it. The $\mathrm{CO}$ molecule acts as a strong field ligand, leading to a large $\mathrm{FeP}-(\mathrm{CO})_{2}$ bond energy $(2.06 \mathrm{eV})$ and relatively short $(1.82$ $\AA$ ) bond length to the metal. The EA increases in the order $\mathrm{FeP}(\mathrm{HCN})_{2}<\mathrm{FeP}(\text { py })_{2}<\mathrm{FeP}($ py $)(\mathrm{CO})<\mathrm{FeP}(\mathrm{CO})_{2}$.

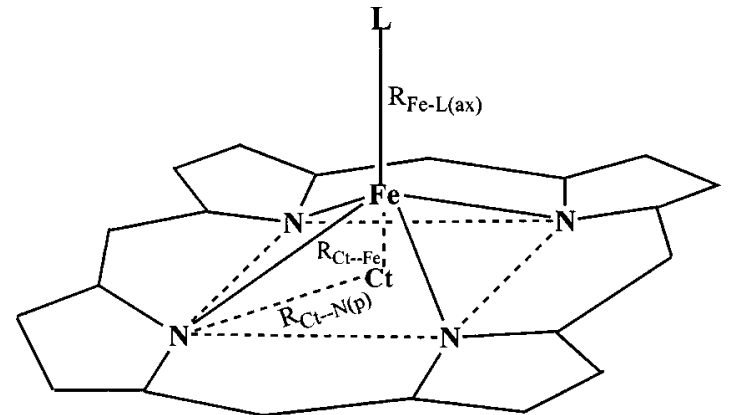

FIG. 4. Coordination group for five-coordinate iron porphyrins $\mathrm{FeP}(L)$. $R_{\mathrm{Ct} \cdot \mathrm{N}(p)}$ denotes the distance between the center of the ring $(\mathrm{Ct})$ and the porphinato nitrogen atom $[\mathrm{N}(p)], R_{\mathrm{Ct} \cdot \mathrm{Fe}}$, the distance between $\mathrm{Ct}$ and $\mathrm{Fe}$, and $R_{\mathrm{Fe}-L(\mathrm{ax})}$ the distance between $\mathrm{Fe}$ and the axial ligand $L$.

\section{C. $\mathrm{FeP}(\mathrm{py})$ and $\mathrm{Fe}(2-\mathrm{Melm})$}

When only a single axial ligand is added to the system, significant out-of-plane distortions are expected and in fact observed. Figure 4 illustrates the three parameters that are used to describe this distortion. $R_{\mathrm{Ct} \cdot \mathrm{N}(p)}$ is a measure of the porphyrin core size, $R_{\mathrm{Ct} \cdot \cdot \mathrm{Fe}}$ represents the separation of $\mathrm{Fe}$ from the plane, and $R_{\mathrm{Re}-\mathrm{L}(\mathrm{ax})}$ refers to the axial ligand-Fe bond length.

To better understand the origin of the distortions observed for the five-coordinate porphyrin, the relevant behavior of the four-coordinate unligated FeP was first examined. Figure 5 illustrates the dependence of the energy of the indicated states upon the size of the porphyrin cage, retaining the metal in the plane. At each spin state and each fixed $R$, the structure of $\mathrm{FeP}$ was reoptimized under the $D_{4 h}$ molecular symmetry. The preference for triplet states is evident for shorter $\mathrm{Fe}-\mathrm{N}(p)$ distances. As this distance is increased, the antibonding $b_{1 g}\left(d_{x^{2}-y^{2}}\right)$ lowers in energy. When $R_{\mathrm{Fe}-\mathrm{N}(p)}$ reaches $2.17 \AA$, one $b_{2 g}\left(d_{x y}\right)$ electron drops into $b_{1 g}$, and the quintet ${ }^{5} A_{1 g}$ becomes the ground state. Thus, a high-spin
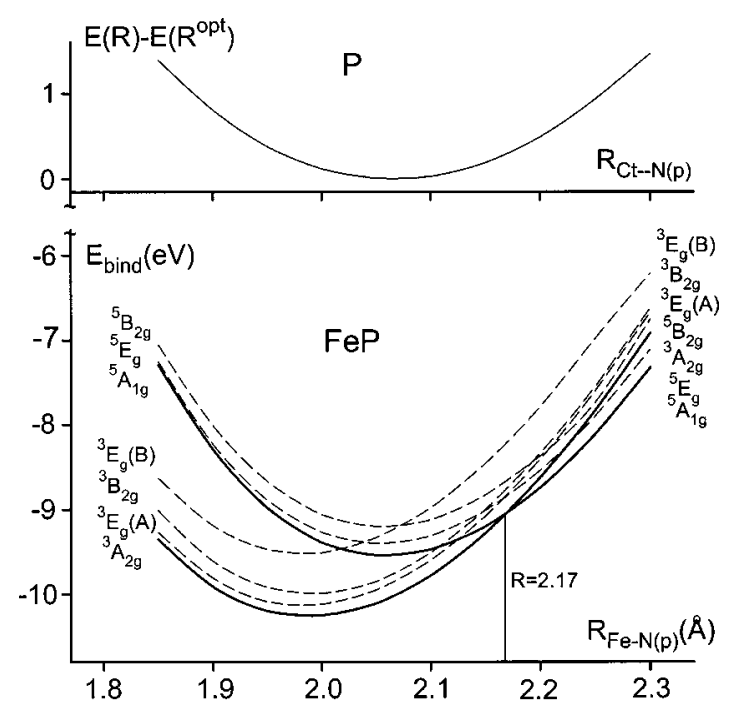

FIG. 5. Variation of the $\mathrm{Fe}-\mathrm{P}$ binding energy $\left(E_{\text {bind }}\right)$ with $\mathrm{Fe}-\mathrm{N}(p)$ distance $\left[E_{\text {bind }}=E(\mathrm{FeP})-E(\mathrm{Fe})-E(\mathrm{P})\right]$. The upper part of the figure shows the variation of the free-base $\mathrm{P}$ energy with the porphyrin core size. 


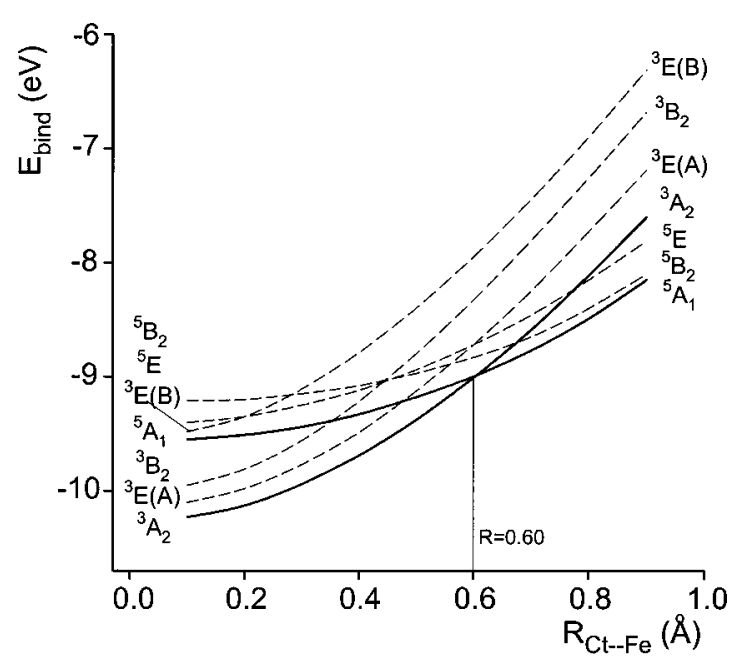

FIG. 6. Variation of the $\mathrm{Fe}-\mathrm{P}$ binding energy $\left(E_{\text {bind }}\right)$ with the Fe out-ofplane displacement $\left[E_{\text {bind }}=E(\mathrm{FeP})-E(\mathrm{Fe})-E(\mathrm{P})\right]$.

ground state of a planar unligated iron porphyrin requires an expansion of the porphinato core.

The sensitivity of the energy of four-coordinate FeP to motion of the metal out of the plane is illustrated in Fig. 6, which clearly indicates that this system prefers planarity in all electronic states considered. This preference is in agreement with other calculations. ${ }^{17,29}$ The potential curves are deeper for the $S=1$ states than for $S=2$ because of the vacancy of the $d_{x^{2}-y^{2}}$ orbital in the former. This absence of electrons facilitates donation from the four $\mathrm{N}$ lone pairs and a consequent strong bonding to the metal. These bonds resist the bending that would result from pulling the metal out of the porphyrin plane. The lowest triplet $\left({ }^{3} A_{2}\right)$ curve intersects with the lowest quintet $\left({ }^{5} A_{1}\right)$ at $R_{\mathrm{Ct} \cdot \mathrm{Fe}} \sim 0.6 \AA$, indicating a switch to high spin at this degree of nonplanarity. One can trace this behavior to the sharp drop in energy experienced by the $d_{x^{2}-y^{2}}$ orbital as the Fe moves out of the plane, dropping it below the $2 e_{1}$ orbital that is the LUMO for smaller nonplanar distortions.

Armed with information about these intrinsic tendencies, attention can now be shifted to the five-coordinate systems. Ligands considered include the six-membered ring pyridine (py), and the five-membered ring of 2-methylimidazole (2MeIm). The systems, illustrated in Fig. 7, corresponding to the different states were optimized. The calculated properties of various electronic configurations of $\mathrm{FeP}(\mathrm{py})$ and $\mathrm{FeP}(2-$ MeIm) are presented in Tables VI and VII, respectively. The states are listed in the same order as in the earlier tables, to more clearly emphasize changes in the energy ordering caused by the fifth coordination site. One very obvious difference with the four-coordinated systems is that double occupation of the $d_{z^{2}}$ orbital [as in the ${ }^{3} A_{2 g},{ }^{3} E_{g}(B)$, and ${ }^{5} A_{1 g}$ states] resulted in a very long $\mathrm{Fe}-\mathrm{N}(\mathrm{ax})$ distance. This result, differing from earlier DFT calculations, ${ }^{29,30}$ implies that ${ }^{3} A_{2 g}$ and ${ }^{5} A_{1 g}$ are not the lowest triplet and quintet in $\mathrm{FeP}(\mathrm{L})$.

\section{1. $F e P(p y)$}

The ground state of $\mathrm{FeP}(\mathrm{py})$ is ${ }^{1} A_{1}:\left(d_{x y}\right)^{2}\left(d_{\pi}\right)^{4}$, as reported in the last row of Table VI. The displacement of Fe from the porphyrin plane is small, only $0.17 \AA$, and the

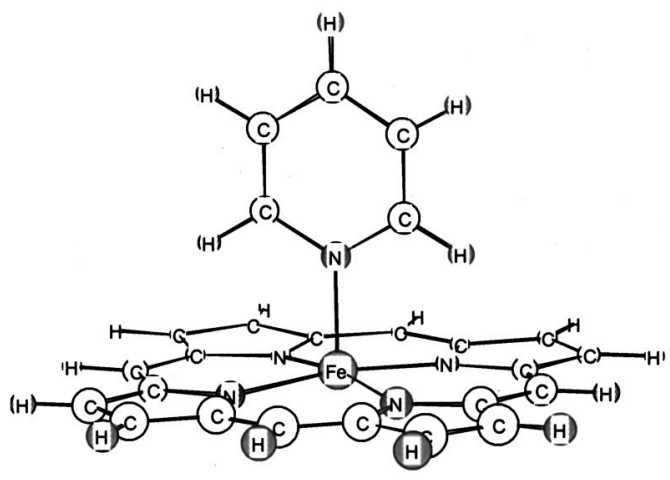

(A) $\mathrm{FeP}($ py)

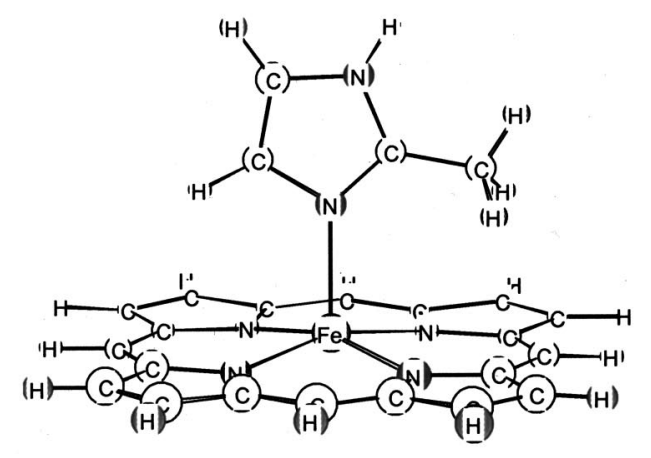

(B) FeP(2-MeIm)

FIG. 7. Optimized structure of FeP(py) (A) and FeP(2-MeIm) (B).

empty $d_{z^{2}}$ orbital is consistent with the short $\mathrm{Fe}-\mathrm{N}(\mathrm{ax})$ bond length. FeP binds pyridine quite tightly, with a bond energy of $0.61 \mathrm{eV} . \mathrm{A}^{3} B_{2}$ state with occupation $\left(d_{x y}\right)^{2}\left(d_{z^{2}}\right)^{1}\left(d_{\pi}\right)^{3}$ is only slightly $(0.16 \mathrm{eV})$ higher in energy, so the multiplicity of the ground state remains somewhat uncertain. The lowest quintet ${ }^{5} B_{1}$ lies nearly $0.8 \mathrm{eV}$ above the ground state.

The calculated $\mathrm{Fe}-\mathrm{N}(p)$ bond lengths for the various states in Table VI are very close to those obtained for FeP, indicating the porphyrin core size is mainly determined by the size of the high-spin $\mathrm{Fe}^{\mathrm{II}}$ ion itself, and less by interactions with the axial ligand. The out-of-plane $\mathrm{Ct} \cdot \cdot$ Fe distance depends on the spin multiplicity; it is $0.15-0.41 \AA$ for $S$ $=2$ and $0.1-0.2 \AA$ for singlets and triplets. That is, the highspin states have considerably larger Fe displacements than do the lower-spin states.

The origin of the Fe out-of-plane displacement has been rationalized on the basis of nonbonded repulsion between the axial ligand and the porphyrin nitrogen orbitals. ${ }^{47}$ The calculated trend in $R_{\mathrm{Ct} . \mathrm{Fe}}$ supports this argument: with the presence of a $d_{x^{2}-y^{2}}$ electron in the high-spin state, the nonbonded repulsion is increased, thereby leading to a relatively large displacement of the $\mathrm{Fe}$ from the porphinato plane. On the other hand, the intermediate- and high-spin states have much longer axial bonds than does the singlet state as a result of their $d_{z^{2}}$ orbital occupancy.

\section{2. $F e P(2-M e I m)$}

Unlike the singlet ground state of $\mathrm{FeP}(\mathrm{py})$, the ground state is computed to correspond to ${ }^{5} A$ : 
TABLE VI. Calculated properties for different configurations of FeP(py) $\left(C_{2 v}\right)$.

\begin{tabular}{|c|c|c|c|c|c|c|c|c|}
\hline \multicolumn{4}{|c|}{ Configuration } & \multirow[b]{2}{*}{ State } & \multirow{2}{*}{$\begin{array}{c}E^{\text {relative }} \\
(\mathrm{eV})\end{array}$} & \multirow{2}{*}{$\underset{(\AA)}{R_{\mathrm{Ct} \cdot \dot{\mathrm{N}}(p)}}$} & \multirow{2}{*}{$\begin{array}{c}R_{\mathrm{Ct} \cdot \mathrm{Fe}} \\
(\AA)\end{array}$} & \multirow{2}{*}{$\begin{array}{l}R_{\mathrm{Fe}-\mathrm{N}(\mathrm{ax}} \\
\quad(\AA)\end{array}$} \\
\hline$d_{x y}$ & $d_{z^{2}}$ & $d_{\pi}$ & $d_{x^{2}-y^{2}}$ & & & & & \\
\hline 2 & 2 & 2 & 0 & $\left.{ }^{3} A_{2}\left({ }^{3} A_{2 g}\right)\right)^{\mathrm{a}}$ & & & & $\ldots \mathrm{b}$ \\
\hline 2 & 1 & 3 & 0 & ${ }^{3} B_{2}\left[{ }^{3} E_{g}(A)\right]$ & 0.16 & 1.99 & 0.15 & 2.17 \\
\hline 1 & 1 & 4 & 0 & ${ }^{3} A_{1}\left({ }^{3} B_{2 g}\right)$ & 0.46 & 2.00 & 0.12 & 2.23 \\
\hline 1 & 2 & 3 & 0 & ${ }^{3} B_{2}\left[{ }^{3} E_{g}(B)\right]$ & & & & $\ldots \mathrm{b}$ \\
\hline 1 & 2 & 2 & 1 & ${ }^{5} A_{1}\left({ }^{5} A_{1 g}\right)$ & 1.32 & 2.05 & 0.15 & 2.79 \\
\hline 1 & 1 & 3 & 1 & ${ }^{5} B_{1}\left({ }^{5} E_{g}\right)$ & 0.78 & 2.05 & 0.29 & 2.16 \\
\hline 2 & 1 & 2 & 1 & ${ }^{5} A_{1}\left({ }^{5} B_{2 g}\right)$ & 0.91 & 2.05 & 0.41 & 2.15 \\
\hline 2 & 0 & 4 & 0 & ${ }^{1} A_{1}\left({ }^{1} A_{1 g}\right)$ & 0 & 1.99 & 0.17 & 1.89 \\
\hline
\end{tabular}

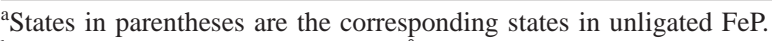

${ }^{\mathrm{b}}$ No minimum or very large (>3.3 $\left.\mathrm{\AA}\right) \mathrm{Fe}-\mathrm{N}(\mathrm{ax})$ distance.

$\left(d_{x y}\right)^{2}\left(d_{z^{2}}\right)^{1}\left(d_{\pi}\right)^{2}\left(d_{x^{2}-y^{2}}\right)^{1}$. This is in agreement with the assignment of Goff and La Mar on the basis of proton NMR data. ${ }^{31}$ The bond energy between FeP and 2-MeIm in the ground state is $0.36 \mathrm{eV}$, notably smaller than that in $\mathrm{FeP}(\mathrm{py})$, where the field strength of pyridine is sufficient to force the $\mathrm{Fe}^{\mathrm{II}}$ into a fully spin paired configuration. For the ground state of $\mathrm{FeP}(2-\mathrm{MeIm})$, the calculation places the Fe $0.29 \AA$ out of the plane, about $0.13 \AA$ smaller than that reported for FeTPP(2-MeIm) EtOH in the crystal structure, where solidstate effects and intermolecular interactions may be responsible for the longer $\mathrm{Ct} \cdot \cdot \mathrm{Fe}$ distance. The calculated $\mathrm{Fe}-\mathrm{N}(p)$ and $\mathrm{Fe}-\mathrm{N}(\mathrm{ax})$ bond lengths are found to compare favorably with the experimental ones.

There are three other states that are not much higher in energy. The order of the four lowest states is ${ }^{5} A\left({ }^{5} B_{2 g}\right)$ $<^{3} A\left[{ }^{3} E_{g}(A)\right]<{ }^{3} A\left({ }^{3} B_{2 g}\right)<{ }^{1} A\left({ }^{1} A_{1 g}\right)$ (parentheses indicate the corresponding states in FeP). A comparison of Table VI with Table VII indicates that the size of the porphyrin ring, as indicated by $R_{\mathrm{Ct} \cdot \mathrm{N}(p)}$, is virtually unaffected by the identity of the axial ligand. For most states, the deviation of the $\mathrm{Fe}$ out of the ring is uniformly slightly larger for 2-MeIm than for pyridine, as is the axial bond length.

Effects of the axial ligand upon the various molecular orbital levels are displayed in Fig. 8. The $d_{z^{2}}$ orbital is strongly destabilized through its interaction with py, while its energy is perturbed to a much lesser degree in $\mathrm{FeP}(2-\mathrm{MeIm})$. Consequently, the double occupation of this $\mathrm{MO}$ in $\mathrm{FeP}$ is diminished to unity in $\mathrm{FeP}(2-\mathrm{MeIm})$ and zero in $\mathrm{FeP}($ py). Regarding the $d_{x^{2}-y^{2}}$ orbital, it is empty in $\mathrm{FeP}(\mathrm{py})$ as it was in FeP, but is lowered enough to be occupied with an electron in $\mathrm{FeP}(2-\mathrm{MeIm})$.

The left and right extremes of Fig. 8 illustrate the energy levels of the unperturbed py and 2-MeIm ligands. In contrast to the two low-lying states of py, 2-MeIm has three. The high energy of the 2-MeIm LUMO leads to a HOMO-LUMO gap that is $1.1 \mathrm{eV}$ larger than that in py. The higher energy of the HOMO in 2-MeIm lowers the ligand field strength, which is further reduced by a likely repulsive interaction between its methyl group and the porphyrin ring. The weaker ligand field lowers the interaction with the Fe $d_{z^{2}}$ orbital, ultimately accounting for the lesser rise in the energy of this orbital. Moreover, Mulliken analysis indicates little mixing of the orbitals of FeP with those of the ligand. This reasoning is supported by earlier work which suggests that spin state is largely determined by the field strength generated by the ligand. ${ }^{48}$

\section{CONCLUSIONS}

The ground states of the unligated (four-coordinate) iron porphyrins were all identified to be triplet ${ }^{3} A_{2 g}$. This result agrees with experimental measurements on FeTPP, ${ }^{3-7}$ but argues against the resonance Raman assignment ${ }^{8}$ of $\mathrm{FeOEP}$ as ${ }^{3} E_{g}$, and the assignment of FeOTBP as ${ }^{5} B_{2 g}$ based on mag-

TABLE VII. Calculated properties for different configurations of FeP (2-MeIm) $\left(C_{1}\right)^{\mathrm{a}}$

\begin{tabular}{|c|c|c|c|c|c|c|c|c|}
\hline \multicolumn{4}{|c|}{ Configuration } & \multirow[b]{2}{*}{ State } & \multirow{2}{*}{$\begin{array}{c}E^{\text {relative }} \\
(\mathrm{eV})\end{array}$} & \multirow{2}{*}{$R_{\mathrm{CC} \cdot \cdot \mathrm{N}(p)}^{(\AA)}$} & \multirow{2}{*}{$\begin{array}{l}R_{\mathrm{C} \cdot \cdot \cdot \mathrm{Fe}} \\
(\AA)\end{array}$} & \multirow{2}{*}{$R_{\mathrm{Fe}-\mathrm{N}(\mathrm{ax}}$} \\
\hline$d_{x y}$ & $d_{z^{2}}$ & $d_{\pi}$ & $d_{x^{2}-y^{2}}$ & & & & & \\
\hline 2 & 2 & 2 & 0 & ${ }^{3} A\left({ }^{3} A_{2 g}\right)^{\mathrm{b}}$ & & & & $\ldots c$ \\
\hline 2 & 1 & 3 & 0 & ${ }^{3} A\left[{ }^{3} E_{g}(A)\right]$ & 0.12 & 1.99 & 0.20 & 2.32 \\
\hline 1 & 1 & 4 & 0 & ${ }^{3} A\left({ }^{3} B_{2 g}\right)$ & 0.26 & 2.00 & 0.15 & 2.38 \\
\hline 1 & 2 & 3 & 0 & ${ }^{3} A\left[{ }^{3} E_{g}(B)\right]$ & & & & $\ldots c$ \\
\hline 1 & 2 & 2 & 1 & ${ }^{5} A\left({ }^{5} A_{1 g}\right)$ & 1.10 & 2.05 & 0.19 & 2.85 \\
\hline 1 & 1 & 3 & 1 & ${ }^{5} A\left({ }^{5} E_{g}\right)$ & 0.70 & 2.05 & 0.34 & 2.17 \\
\hline 2 & 1 & 2 & 1 & ${ }^{5} A\left({ }^{5} B_{2 g}\right)$ & 0 & 2.06 & 0.29 & 2.20 \\
\hline 2 & 0 & 4 & 0 & ${ }^{1} A\left({ }^{1} A_{1 g}\right)$ & 0.34 & 1.99 & 0.21 & 2.04 \\
\hline \multicolumn{4}{|c|}{$\begin{array}{l}\text { Experimental distances in crystal } \\
\text { FeTPP }(2-\mathrm{MeIm}) \cdot \text { EtOH (Ref. 26) }\end{array}$} & & & 2.05 & 0.42 & 2.16 \\
\hline
\end{tabular}

${ }^{a}$ No symmetry was imposed for the geometry optimization.

${ }^{\mathrm{b}}$ States in parentheses are the corresponding states in unligated FeP.

${ }^{\mathrm{c}} \mathrm{No}$ minimum or very large $(>3.4 \AA) \mathrm{Fe}-\mathrm{N}(\mathrm{ax})$ distance. 


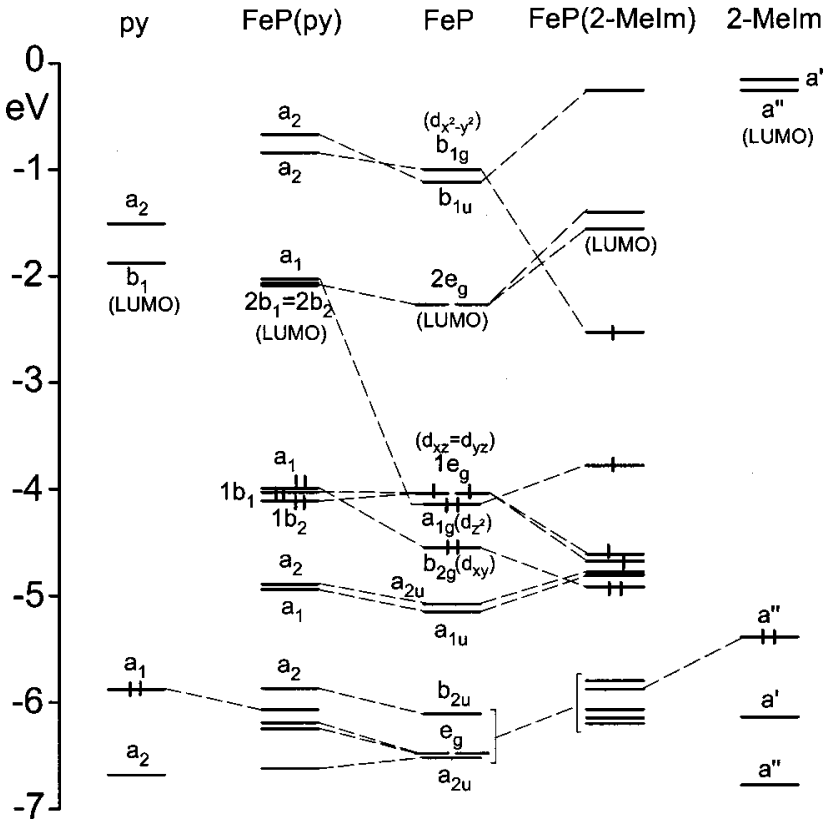

FIG. 8. Orbital energy level diagrams of FeP, FeP(py), and FeP(2-MeIm), as well as the py and 2-MeIm molecules.

netic and Mössbauer measurements in the early literature. ${ }^{18}$ The alternation of the porphyrin ligand does not have strong effects on the relative energetics of the spin states of $\mathrm{Fe}^{\mathrm{II}}$ in unligated iron porphyrin. The calculated excitation energies, $\mathrm{Fe}$-porphyrin bond energies, ionization potentials, and electron affinities agree very well with available experimental data. The electronic properties of FeOTBP differ somewhat from those of $\mathrm{FeP}$ due to the presence of benzo groups and longer $\mathrm{Fe}-\mathrm{N}(p)$ bond length in the former molecule. The one-electron oxidations of FeP, FeTPP, and FeOEP are metal-centered, while it occurs at the ring for FeOTBP.

Upon complexation by two strong-field axial ligands $L\left(L=\mathrm{HCN}\right.$, py, CO), $\operatorname{FeP}(L)_{2}$ becomes low-spin $(S=0)$, having a ground state configuration of $\left(d_{x y}\right)^{2}\left(d_{\pi}\right)^{4}$. The site of oxidation in $\operatorname{FeP}(L)_{2}$ depends on the nature and ligandfield strength of $L$, in accord with experimental observation. The calculated first IPs correlate nicely with the measured oxidation potentials.

As models for deoxyheme in hemoprotein, $\mathrm{FeP}(\mathrm{py})$ and $\mathrm{FeP}(2-\mathrm{MeIm})$ were investigated by considering all possible low-lying states. The ground-state configuration of $\mathrm{FeP}(2-\mathrm{MeIm})$ was calculated to be high-spin $\left(d_{x y}\right)^{2}\left(d_{z^{2}}\right)^{1}\left(d_{\pi}\right)^{2}\left(d_{x^{2}-y^{2}}\right)^{1}$, in agreement with experimental assignment. ${ }^{31}$ Because the optimized $\mathrm{Ct} \cdot \cdot$ Fe distance is significantly smaller than the experimental one, the so-called nonbonded repulsion ${ }^{47}$ may only be partially responsible for the large Fe out-of-plane displacement in FeTPP(2MeIm) $\cdot \mathrm{EtOH}$ or in the deoxyheme complexes. The nature of bonding in $\mathrm{FeP}(\mathrm{py})$ is different from that in $\mathrm{FeP}(2-\mathrm{MeIm})$; the former molecule has a low-spin ground state. Py is not an appropriate mimic for imidazole.

\section{ACKNOWLEDGMENT}

This work was supported by Grant No. DAAD19-99-10206 from the Army Research Office.
${ }^{1}$ Iron Porphyrin, edited by A. B. P. Lever and H. B. Gray (AddisonWesley, Reading, 1983).

${ }^{2}$ W. R. Scheidt and C. R. Reed, Chem. Rev. 81, 543 (1981).

${ }^{3}$ J. P. Collman, J. L. Hoard, N. Kim, G. Lang, and C. A. Reed, J. Am. Chem. Soc. 97, 2676 (1975).

${ }^{4}$ G. Lang, K. Spartalian, C. A. Reed, and J. P. Collman, J. Chem. Phys. 69, 5424 (1978).

${ }^{5}$ P. D. W. Boyd, A. D. Buckingham, R. F. McMecking, and S. Mitra, Inorg. Chem. 18, 3585 (1979).

${ }^{6}$ H. Goff, G. N. La Mar, and C. A. Reed, J. Am. Chem. Soc. 99, 3641 (1977).

${ }^{7}$ J. Mispelter, M. Momenteau, and J. M. Lhoste, J. Chem. Phys. 72, 1003 (1980).

${ }^{8}$ T. Kitagawa and J. Teraoka, Chem. Phys. Lett. 63, 443 (1979).

${ }^{9}$ H. Kashiwagi and S. Obara, Int. J. Quantum Chem. 20, 843 (1981).

${ }^{10}$ A. Dedieu, M.-M. Rohmer, and A. Veillard, Adv. Quantum Chem. 16, 43 (1982).

${ }^{11}$ M.-M. Rohmer, Chem. Phys. Lett. 116, 44 (1985).

${ }^{12}$ D. C. Rawlings, M. Gouterman, E. R. Davidson, and D. Feller, Int. J. Quantum Chem. 28, 773 (1985).

${ }^{13}$ Y.-K. Choe, T. Nakajima, and K. Hirao, J. Chem. Phys. 111, 3837 (1999); Y.-K. Choe, T. Hashimoto, H. Nakano, and K. Hirao, Chem. Phys. Lett. 295, 380 (1998)

${ }^{14}$ (a)S. F. Sontum, D. A. Case, and M. Karplus, J. Chem. Phys. 79, 2881 (1983); (b) W. D. Edwards, B. Weiner, and M. C. Zerner, J. Am. Chem. Soc. 108, 2196 (1986).

${ }^{15}$ B. Delley, Physica B 172, 185 (1991).

${ }^{16}$ N. Matsuzawa, M. Ata, and D. A. Dixon, J. Phys. Chem. 99, 7698 (1995).

${ }^{17}$ P. M. Kozlowski, T. G. Spiro, A. Bérces, and Z. Zgierski, J. Phys. Chem. B 102, 2603 (1998).

${ }^{18}$ J. R. Sams and T. B. Tsin, Chem. Phys. Lett. 25, 599 (1974).

${ }^{19}$ M. J. Stillman and A. J. Thomson, J. Chem. Soc., Faraday Trans. 2 70, 790 (1974).

${ }^{20}$ H. Kobayashi and Y. Yanagawa, Bull. Chem. Soc. Jpn. 45, 450 (1972).

${ }^{21}$ L. J. Radonovich, A. Bloom, and J. L. Hoard, J. Am. Chem. Soc. 94, 2073 (1972).

${ }^{22}$ S.-M. Peng and J. A. Ibers, J. Am. Chem. Soc. 98, 8032 (1976).

${ }^{23}$ C. A. Reed, T. Mashiko, W. R. Scheidt, K. Spartalian, and G. Lang, J. Am. Chem. Soc. 102, 2302 (1980).

${ }^{24}$ Our DFT calculations on isolated $\mathrm{FeP}(\mathrm{THF})_{2}$ suggest a low-spin $(S=0)$ and an intermediate-spin $(S=1)$ site to be nearly degenerate. At the experimental geometry, the complex was computed to be of intermediate spin, differing from experimental assignment to high spin. More detailed investigations would be worthwhile.

${ }^{25}$ (a)M. F. Perutz, Nature (London) 228, 726 (1970); (b) M. Momenteau and C. A. Reed, Chem. Rev. 94, 659 (1994).

${ }^{26}$ G. B. Jameson, F. S. Molinaro, J. A. Ibers, J. P. Collman, J. I. Brauman, E. Rose, and K. S. Suslick, J. Am. Chem. Soc. 100, 6769 (1978).

${ }^{27}$ S. Obara and H. Kashiwagi, J. Chem. Phys. 77, 3155 (1982).

${ }^{28}$ G. H. Loew, in Iron Porphyrin, edited by A. B. P. Lever and H. B. Gray (Addison-Wesley, Reading, 1983), Part One, pp. 1-87.

${ }^{29}$ C. Rovira, K. Kunc, J. Hutter, P. Ballone, and M. Parrinello, J. Phys. Chem. A 101, 8914 (1997).

${ }^{30}$ P. M. Kozlowski, T. G. Spiro, and M. Z. Zgierski, J. Phys. Chem. B 104, 10659 (2000).

${ }^{31}$ H. Goff and G. N. La Mar, J. Am. Chem. Soc. 99, 6599 (1977).

${ }^{32}$ M.-S. Liao and S. Scheiner, J. Chem. Phys. 114, 9780 (2001).

${ }^{33}$ M.-S. Liao and S. Scheiner, J. Chem. Phys. (submitted).

${ }^{34}$ T. Ziegler, A. Rauk, and E. J. Baerends, Theor. Chim. Acta 43, 261 (1977); R. O. Jones and O. Gunnarsson, Rev. Mod. Phys. 61, 689 (1989).

${ }^{35}$ P. Cocolios and K. M. Kadish, Isr. J. Chem. 25, 138 (1985).

${ }^{36}$ (a) J. P. Collman, Acc. Chem. Res. 10, 265 (1977); (b) J. P. Collman and C. A. Reed, J. Am. Chem. Soc. 95, 2048 (1973).

${ }^{37}$ ADF program package, version 2.0.1, E. J. Baerends, D. E. Ellis, and P. Ros, Chem. Phys. 2, 41 (1973); G. te Velde and E. J. Baerends, J. Comput. Phys. 99, 84 (1992).

${ }^{38}$ S. H. Vosko, L. Wilk, and M. Nusair, Can. J. Phys. 58, 1200 (1980).

${ }^{39}$ A. D. Becke, Phys. Rev. A 38, 3098 (1988).

${ }^{40}$ J. P. Perdew and Y. Wang, Phys. Rev. B 33, 8800 (1986).

${ }^{41}$ T. Ziegler, V. Tschinke, E. J. Baerends, J. G. Snijders, and W. Ravenek, J. Phys. Chem. 93, 3050 (1989).

${ }^{42}$ C. Weiss, H. Kobayashi, and M. Gouterman, J. Mol. Spectrosc. 16, 415 (1965).

${ }^{43}$ S. C. Khandelwal and J. L. Roebber, Chem. Phys. Lett. 34, 355 (1975). 
${ }^{44}$ S. Kitagawa, I. Morishima, T. Yonezawa, and N. Sato, Inorg. Chem. 18, 1345 (1979).

${ }^{45}$ H. L. Chen, P. E. Ellis, Jr., T. Wijesekera, T. E. Hagan, S. E. Groh, J. E. Lyons, and D. P. Ridge, J. Am. Chem. Soc. 116, 1086 (1994).

${ }^{46}$ G. M. Brown, F. R. Hopf, T. J. Meyer, and D. G. Whitten, J. Am. Chem.
Soc. 97, 5385 (1975); G. M. Brown, F. R. Hopf, J. A. Ferguson, T. J. Meyer, and D. G. Whitten, ibid. 95, 5939 (1973).

${ }^{47}$ B. D. Olafson and W. A. Goddard III, Proc. Natl. Acad. Sci. U.S.A. 74, 1315 (1977).

${ }^{48}$ C. A. Reed and F. Guiset, J. Am. Chem. Soc. 118, 3281 (1996). 